\title{
Laminar CuO-water nano-fluid flow and heat transfer in a backward-facing step with and without obstacle
}

\author{
Hussein Togun ${ }^{1}$
}

Received: 17 February 2015/Accepted: 19 March 2015/Published online: 4 April 2015

(c) The Author(s) 2015. This article is published with open access at Springerlink.com

\begin{abstract}
This paper presents a numerical investigate on $\mathrm{CuO}$-water nano-fluid and heat transfer in a backwardfacing step with and without obstacle. The range of Reynolds number varied from 75 to 225 with volume fraction on $\mathrm{CuO}$ nanoparticles varied from 1 to $4 \%$ at constant heat flux was investigated. Continuity, momentum, and energy equations with finite volume method in two dimensions were employed. Four different configurations of backwardfacing step (without obstacle, with obstacle of $1.5 \mathrm{~mm}$, with obstacle of $3 \mathrm{~mm}$, with obstacle of $4.5 \mathrm{~mm}$ ) were considered to find the best thermal performance. The results show that the maximum augmentation in heat transfer was about $22 \%$ for backward-facing step with obstacle of $4.5 \mathrm{~mm}$ and using $\mathrm{CuO}$ nanoparticles at Reynolds number of 225 compared with backward-facing step without obstacle. It is also observed that increase in size of recirculation region with increase of height obstacle on the channel wall has remarkable effect on thermal performance. The results also found that increases in Reynolds number, height obstacle, and volume fractions of $\mathrm{CuO}$ nanoparticles lead to increase of pressure drop.
\end{abstract}

Keywords Laminar flow - Thermal performance . Separation flow $\cdot$ Backward-facing step $\cdot$ Nano-fluids

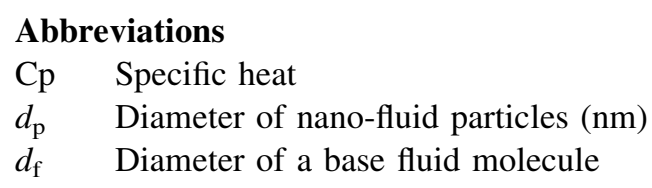

Hussein Togun

htokan_2004@yahoo.com; htokan_eng@yahoo.co.uk

1 Department of Mechanical Engineering, University of Thi-Qar, 64001 Nassiriya, Iraq
$\mathrm{Nu} \quad$ Nusselt number
$P \quad$ Pressure
Pr Prandtl number
Re Reynolds number
$u, v \quad$ Axial velocity
$X, Y$ Cartesian coordinates

\section{Greek symbols}

$\rho \quad$ Density

$\beta \quad$ Modeling function

$\mu \quad$ Dynamic viscosity

$\mu_{\text {eff }}$ Effective dynamic viscosity

$\phi \quad$ Volume fraction (\%)

\section{Introduction}

Due to the global energy crisis, many different methods were used to increase the thermal performance in heatexchanging equipment. Modification in flow geometry is one of common technique which is used to enhance heat transfer rate such as expansion or contraction in channel, use rib on wall of channel, insert twist tape through passage flow, etc. In the recent years, nano-fluids have received extensive attention due to its higher thermal conductivity compared with normal cooling fluid. Addad et al. (2003) presented numerical study on fluid flow over forwardbackward-facing step using Large Eddy Simulation (LES). They found that the separation length and reattachment offset were about 1.2 and 0.6 from step height, respectively. While $\mathrm{Yu}$ et al. (2009) presented numeircal study in 2D and 3D dimension of fluid flow over a backward facing step at low and high Reynolds number with assume twophase. In their study, LES was used where good agreement noted between 2D and 3D numerical data with

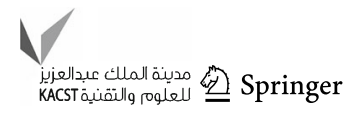


experimental data in profile of both velocity and temperature. Laminar, transition, and turbulent fluid flow over backward-facing step were experimentally and numerically studied by Armaly et al. (1983). The results revealed the increase in separation length with increase of Reynolds number for $\operatorname{Re}<1200$ but decrease at Re between 1200 and 5550. Khanafer et al. (2008) used finite element method for analysis of laminar heat transfer convection of pulsatile flow over a backward-facing step. Enhancement of heat transfer rate was observed with increase of Reynolds number while decrease in thickness of the thermal boundary layer. Laminar fluid flow and heat transfer between parallel plates through baffles were numerically investigated by Kelkar and Patankar (1987). Increase in size recirculation regions, Nusselt number, and friction coefficient was found with increase of Reynolds number. Lima et al. (2008) investigated numerically study of two-dimensional laminar air flows over backward-facing step using two CFD commercial codes, the first one based on finite element method (COMSOL MULTIPHYSICS) and the other based on finite volume method (FLUENT) and the range of Reynolds number. The numerical results agree with previous experimental data and those result also appeared there are non-linear increase in reattachment length.

Different equipments have been used to measure heat transfer near the reattached point of the separated flows, and Mori Yuaks (1986) used the thermal tuft probe, but Kawamura et al. (1987) designed new heat flux probe to find the time and spatial characteristics of heat transfer at the reattachment region of a two-dimensional backwardfacing step deign. Oyakawa et al. (1996) also used jet discharge at reattachment region downstream of backwardfacing step.

Turbulent heat transfer and fluid flow through annular pipe with sudden expansion were experimentally and numerically studied by Togun et al. (2011) and Oon et al. (2012). The results showed that the highest enhancement of heat transfer was about $18 \%$ at step height $18.5 \mathrm{~mm}$ compared to without step.

Recently, effect of use nano-fluid has been studied in many researches due to increase in thermal performance. Abu-Nada (2008) can be considering as a pioneer in numerical study of heat transfer to nano-fluid over backwardfacing step. The type of nanoparticles in this study was represented by $\mathrm{Cu}, \mathrm{Ag}, \mathrm{Al}_{2} \mathrm{O}_{3}$, Cuo, and $\mathrm{TiO}_{2}$ with volume friction between 0.05 and 0.2 and range of Reynolds number from 200 to 600 . Momentum and energy equations were solved using finite volume method which observed increase of Nusselt number at the top and bottom of the backward-facing step. Also the investigations found high thermal conductivity of nanoparticles as outside of recirculation zones. Later, Togun et al. (2014a) presented numerical study of nano-fluid flow and heat transfer over a backward-facing step. The higher thermal performance was about 26 and $36 \%$ for turbulent and laminar range, respectively, compared with pure water. Turbulent heat transfer of water/functionalized multi-walled carbon nanotube (FMWCNT) nano-fluids over a forward-facing step was numerically investigated by Safaei et al. (2014). The results showed that increase for both Reynolds number and FMWCNT volume fraction leads to increase in local heat transfer coefficient for all cases. Turbulent nano-fluid flow and heat transfer over double forward-facing steps were studied numerically by Togun et al. (2015). They found that the maximum Nusselt number happened at the second step compared to the first step and the biggest thermal improvement occurred at volume fraction $(4 \%)$ of $\mathrm{Al}_{2} \mathrm{O}_{3}$ compared with others.

The goal of the current research was to study the laminar nano-fluid flow and heat transfer over backward-facing step with and without obstacle. In this research, effort to present new data for using nano-fluids and obstacle with backwardfacing step will be more useful to design heat exchanger with higher thermal performance.

\section{Geometry and boundary conditions}

Figure 1a, b show the geometry which used in this investigation with same dimensions as established by Togun et al. (2014b). The considered geometry was represented
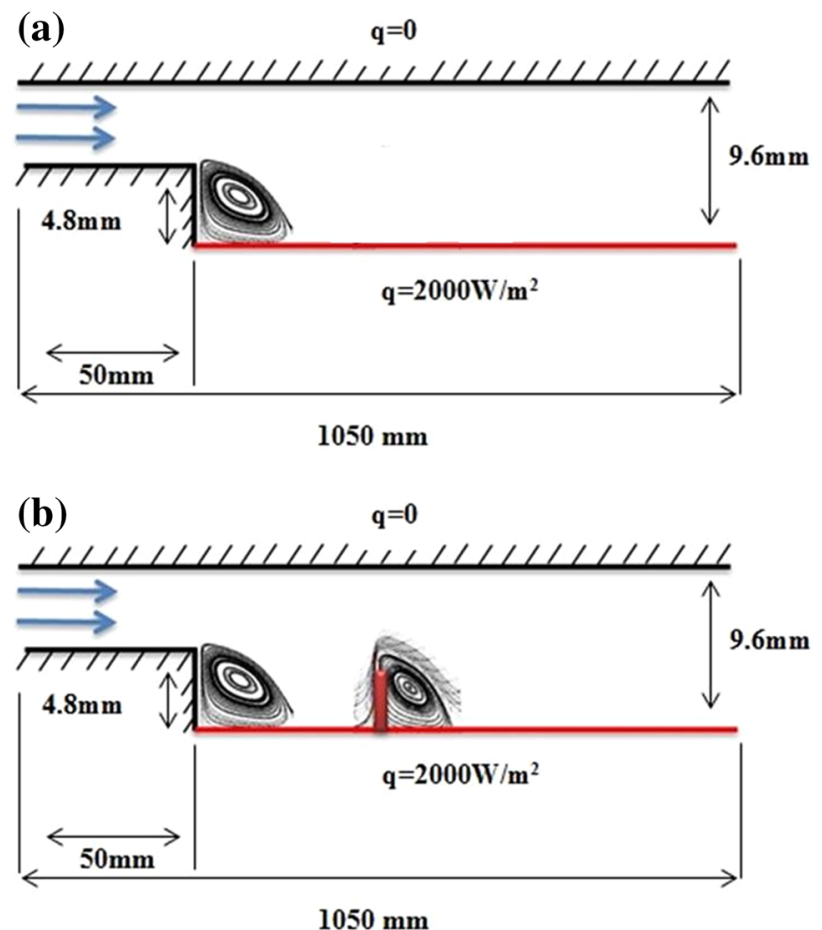

Fig. 1 Flow configuration of the computational domain of backwardfacing step (a) without obstacle (b) with obstacle 
by backward-facing step of channel with and without obstacle. The diameter of the inlet and outlet channel is 4.8 and $9.6 \mathrm{~mm}$, respectively with unheated upstream length is $50 \mathrm{~mm}$ and heated downstream length is $1000 \mathrm{~mm}$ at $2000 \mathrm{~W} / \mathrm{m}^{2}$. Three different heights of obstacle of $1.5,3$, 4.5 , and $1.5 \mathrm{~mm}$ width were fixed at $200 \mathrm{~mm}$ from the step with expansion ratio 2. Volume fraction of $\mathrm{CuO}$ nano-fluid varied between 1 and $4 \%$ at Reynolds numbers of 75, 125, 175 , and 225 .

\section{Numerical procedure}

\section{Governing equations}

Two-dimensional continuity, momentum $(X, Y)$, and energy equations with assumption laminar, steady state, and incompressible are used in this model and are given as (1, 2, 3, 4).

$\frac{\partial u}{\partial x}+\frac{\partial v}{\partial y}=0$

$u \frac{\partial u}{\partial x}+v \frac{\partial u}{\partial y}=-\frac{1}{\rho} \frac{\partial p}{\partial x}+v\left(\frac{\partial^{2} u}{\partial x^{2}}+\frac{\partial^{2} u}{\partial y^{2}}\right)$

$u \frac{\partial v}{\partial x}+v \frac{\partial v}{\partial y}=-\frac{1}{\rho} \frac{\partial p}{\partial y}+v\left(\frac{\partial^{2} v}{\partial x^{2}}+\frac{\partial^{2} v}{\partial y^{2}}\right)$

$u \frac{\partial T}{\partial x}+v \frac{\partial T}{\partial y}=-\frac{1}{\rho} \frac{\partial p}{\partial y}+\propto\left(\frac{\partial^{2} T}{\partial x^{2}}+\frac{\partial^{2} T}{\partial y^{2}}\right)$

The hydrodynamic boundary conditions are At the channel wall surface: $u=v=0$ (no slip), Inlet: $u=$ based on Re, $v=0, y=L ; P=P_{\text {out }}$ at the outlet. The Reynolds number is calculated based on inlet channel height $(H)$.

$R e=\frac{u H}{v}$

\section{Grid testing and model validation}

Two-dimensional viscous laminar model with energy dialog box was used to solve continuity, momentum, and energy equations. The second-order upwind method of Patankar (1980) was selected for the discretization of all terms in equations. The SIMPLE algorithm for pressurevelocity coupling was used by Emad et al. (2015). In this simulation, the residual of solution was smaller than $10^{-4}$ for continuity equation, $10^{-7}$ for momentum equations, and $10^{-8}$ for energy equation. Non-uniform quadrilateral grids were used to increase accuracy of solution which increases density of mesh near regions of backward and obstacle highly than other parts. The criteria of grid independent were represented using three different size of grid at $\operatorname{Re}=175$, see Fig. 2. Due to the difference in Nusselt number for grid number 3 and 2 was about $2 \%$ then the

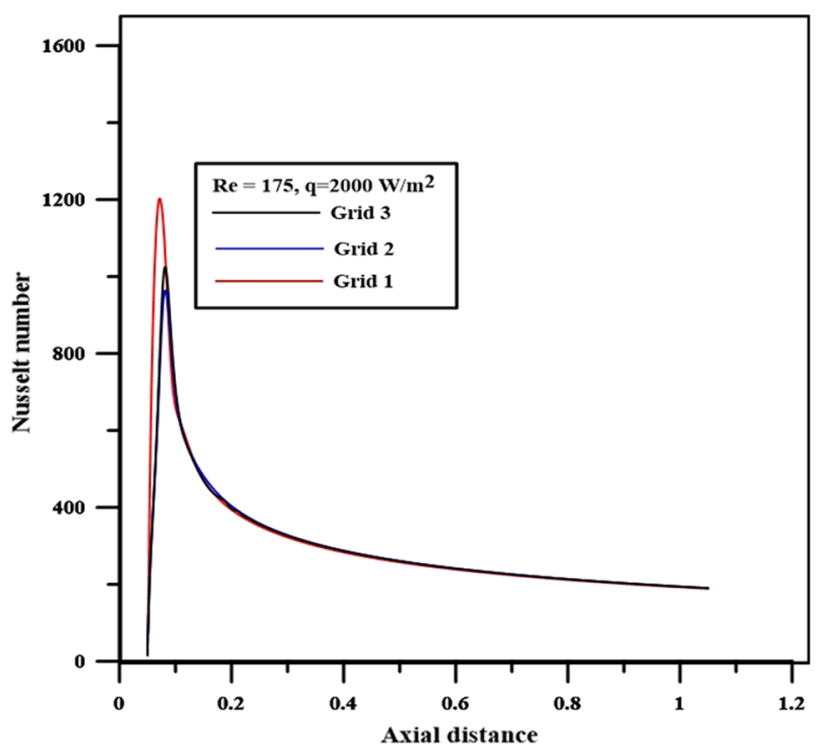

Fig. 2 Grid independent for Reynolds number 175 and pure water

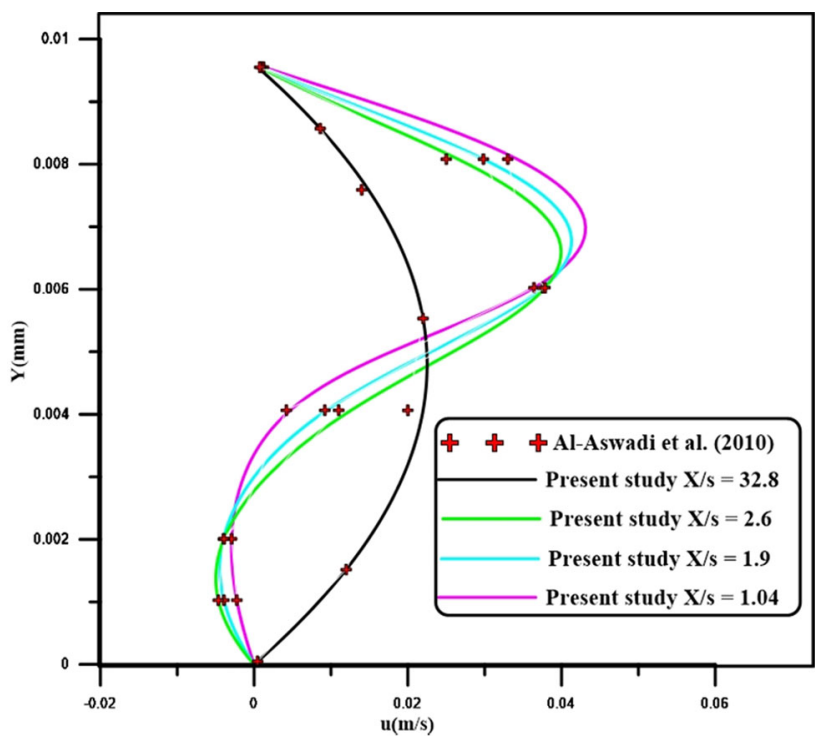

Fig. 3 Comparison velocity profile of present study with Al-aswadi et al. (2010)

grid number 2 can be considered as a grid independent. For more validations, compared with the work of Al-aswadi et al. (2010) for computed X-velocity of $\mathrm{Cu} /$ water nanofluid at $\mathrm{Re}=175$ where the results showed good agreement as shown in Fig. 3.

\section{Thermophysical properties of the nano-fluid}

Thermophysical properties of the nano-fluid are calculated by specific correlations. The effective density of nano-fluid is written as (Vajjha and Das 2009) 
$\rho_{\mathrm{nf}}=(1-\phi) \rho_{\mathrm{f}}+\phi \rho_{\mathrm{np}}$,

where $\rho_{\mathrm{f}}$ and $\rho_{\mathrm{np}}$ define the density of base fluid and the solid nanoparticles, respectively.

The heat capacity of the nano-fluid is presented by (Vajjha and Das 2009)

$\left(\rho C_{\mathrm{p}}\right)_{\mathrm{nf}}=(1-\phi)\left(\rho C_{\mathrm{p}}\right)_{\mathrm{f}}+\phi\left(\rho C_{\mathrm{p}}\right)_{\mathrm{np}}$,

where $\left(\rho C_{\mathrm{p}}\right)_{\mathrm{f}}$ and $\left(\rho C_{\mathrm{p}}\right)_{\mathrm{np}}$ define the heat capacities of the base fluid and the nanoparticles, respectively.

As observed by Koo and Kleinstreuer (2005), the effective thermal conductivity of nano-fluid contains static and Brownian effects and calculated with the following empirical correlations:

$K_{\text {eff }}=K_{\text {static }}+K_{\text {Brownian }}$

$K_{\text {static }}=K_{\mathrm{f}}\left[\frac{\left(K_{\mathrm{np}}+2 K_{\mathrm{f}}\right)-2 \phi\left(K_{\mathrm{f}}-K_{\mathrm{np}}\right)}{\left(K_{\mathrm{np}}+2 K_{\mathrm{f}}\right)+\phi\left(K_{\mathrm{f}}+K_{\mathrm{np}}\right)}\right]$

$K_{\text {Brownian }}=5 \times 10^{4} \beta \phi \rho_{\mathrm{f}} C_{\mathrm{p}, \mathrm{f}} \sqrt{\frac{K T}{2 \rho_{\text {np }} d_{\mathrm{p}}}} \mathrm{f}(T, \phi)$,

where $k=1.3809 \times 10^{-23} \mathrm{~J} / \mathrm{K}$ is the Boltzmann constant, and $\beta$ is given as

$\beta=8.4407(100 \phi)^{-1.07304}$

and $\mathrm{f}(T, \phi)$ is given as

$$
\begin{aligned}
\mathrm{f}(T, \phi)= & \left(2.8217 \times 10^{-2} \phi+3.917 \times 10^{-3}\right)\left(\frac{T}{T_{\circ}}\right) \\
& +\left(-3.0669 \times 10^{-2} \phi-3.91123 \times 10^{-3}\right)
\end{aligned}
$$

The effective dynamic viscosity for the nano-fluid could be calculated by the following equations (Corcione 2010):

$\mu_{\text {eff }}=\mu_{\mathrm{f}} \times \frac{1}{\left(1-34.87\left(d_{\mathrm{p}} / d_{\mathrm{f}}\right)^{-0.3} \times \phi^{1.03}\right)}$

$d_{\mathrm{f}}=\left(\frac{6 M}{N \pi \rho_{\mathrm{f} 0}}\right)^{1 / 3}$,

where $d_{\mathrm{p}}$ and $d_{\mathrm{f}}$ represented the mean diameter of the nanoparticles and equivalent diameter of a base fluid molecule, respectively; $M$ represented the molecular weight; $N$ represented the Avogadro number $=6.022 \times 10^{23} \mathrm{~mol}^{-1}$; and $\rho_{\mathrm{fo}}$ is the density of the base fluid found at Temperature $=293 \mathrm{~K}$.

Table 1 shows the thermophysical properties of the nano-fluid Corcione (2010) and water Incropera (2007).The Nusselt number is defined as

$N u=\frac{h d}{k}$,

where $h$ is the heat transfer coefficient.
Table 1 Thermophysical properties of nanoparticles $(\mathrm{CuO})$ and water at $T=300 \mathrm{~K}$

\begin{tabular}{lll}
\hline $\begin{array}{l}\text { Thermophysical } \\
\text { properties }\end{array}$ & $\begin{array}{l}\text { CuO Corcione } \\
(2010)\end{array}$ & $\begin{array}{l}\text { Water Incropera } \\
(2007)\end{array}$ \\
\hline$\rho\left(\mathrm{kg} / \mathrm{m}^{3}\right)$ & 6500 & 996.5 \\
$C \mathrm{p}(\mathrm{J} / \mathrm{kg} \mathrm{k})$ & 533 & 4181 \\
$K(\mathrm{~W} / \mathrm{m} \mathrm{k})$ & 17.65 & 0.613 \\
$\mu\left(\mathrm{Ns} / \mathrm{m}^{2}\right)$ & - & $1 \mathrm{E}-03$ \\
\hline
\end{tabular}

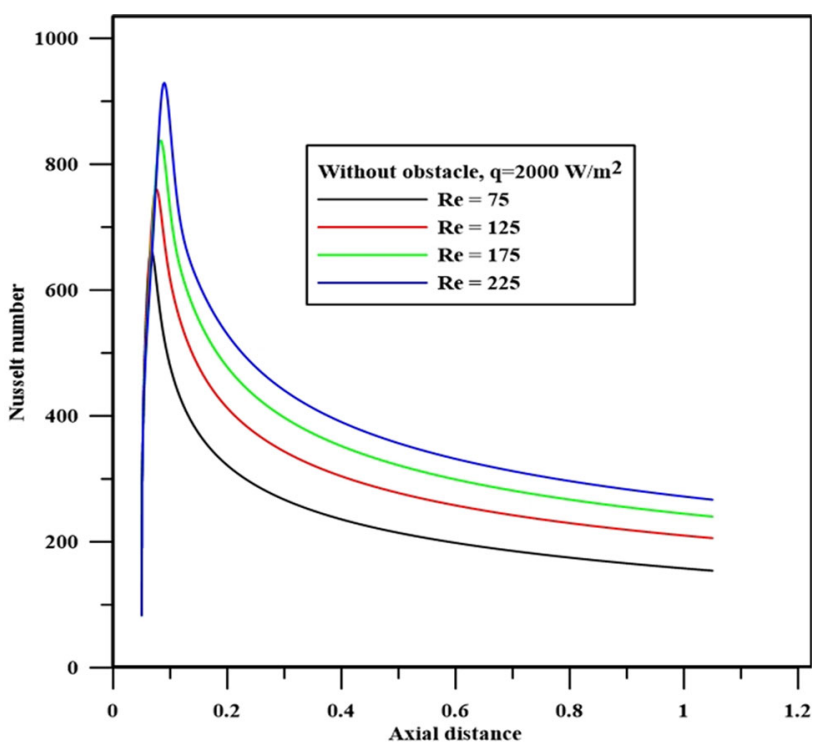

Fig. 4 Effect of Reynolds number on local Nusselt number for backward-facing step without obstacle

\section{Result and discussion}

\section{Effect of Reynolds number}

The effects of Reynolds number on local Nusselt number for flow over backward-facing step without obstacle are presented in Fig. 4. It can be seen that the local Nusselt number increases with increase of Reynolds number for all cases where the maximum Nusselt number observed with higher Reynolds number due to increase of recirculation region which created after step. Figure 5 shows the variation of pressure drop with axial distance at different Reynolds number. The results showed the rise of pressure drop with Reynolds number due to the hydrodynamics of the flow.

\section{Effect of height obstacle}

Four different configurations of backward-facing step (without obstacle, with obstacle of $1.5 \mathrm{~mm}$, with obstacle of $3 \mathrm{~mm}$, with obstacle of $4.5 \mathrm{~mm}$ ) are conducted in this 


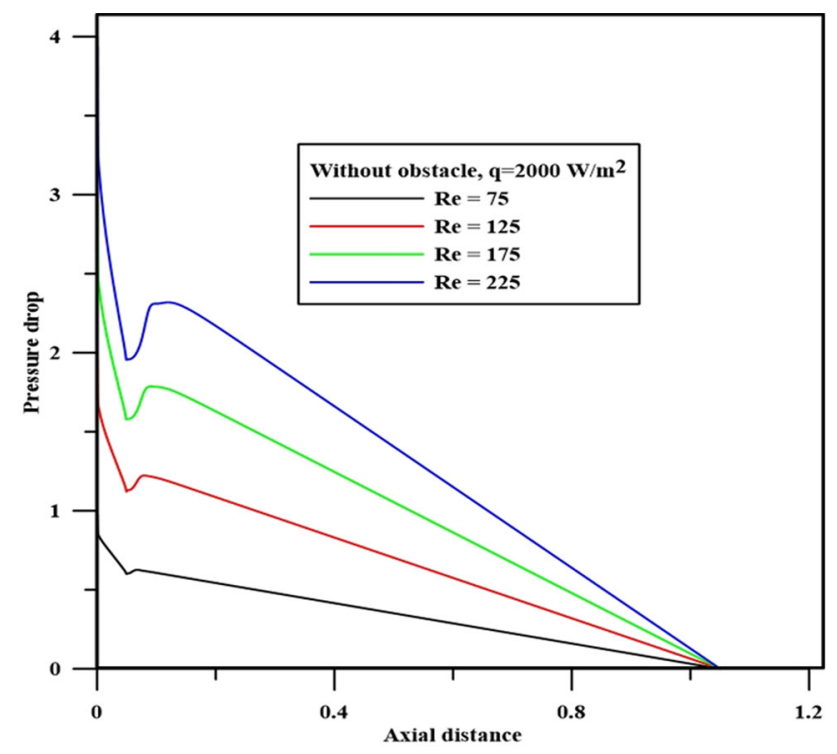

Fig. 5 Effect of Reynolds number on pressure drop for backwardfacing step without obstacle

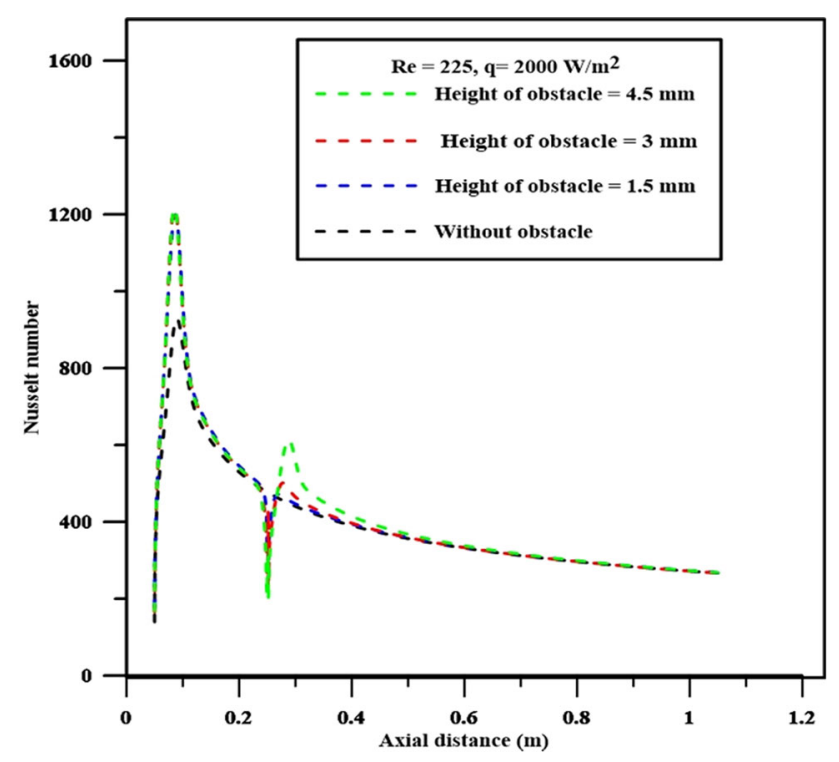

Fig. 6 Effect of height obstacle on local Nusselt number

study. Figures 6, 7 illustrate the effect of height obstacle on local Nusselt number and pressure drop with axial distance at Reynolds number of 225 and heat flux $2000 \mathrm{~W} / \mathrm{m}^{2}$, respectively. Generally, local Nusselt number and pressure drop found increases with increased of height obstacle due to recirculation regions as created after and before the obstacle and at inlet region of backward facing step. The highest Nusselt number and pressure drop are observed at backward-facing step with height obstacle of $4.5 \mathrm{~mm}$ and Reynolds number of 225 compared with others.

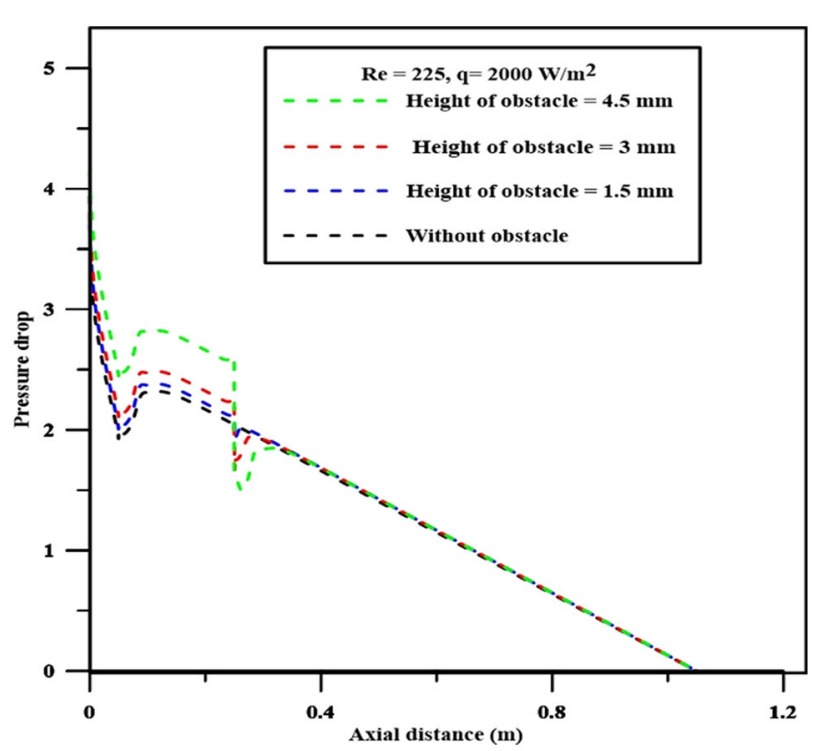

Fig. 7 Effect of height obstacle on local pressure drop

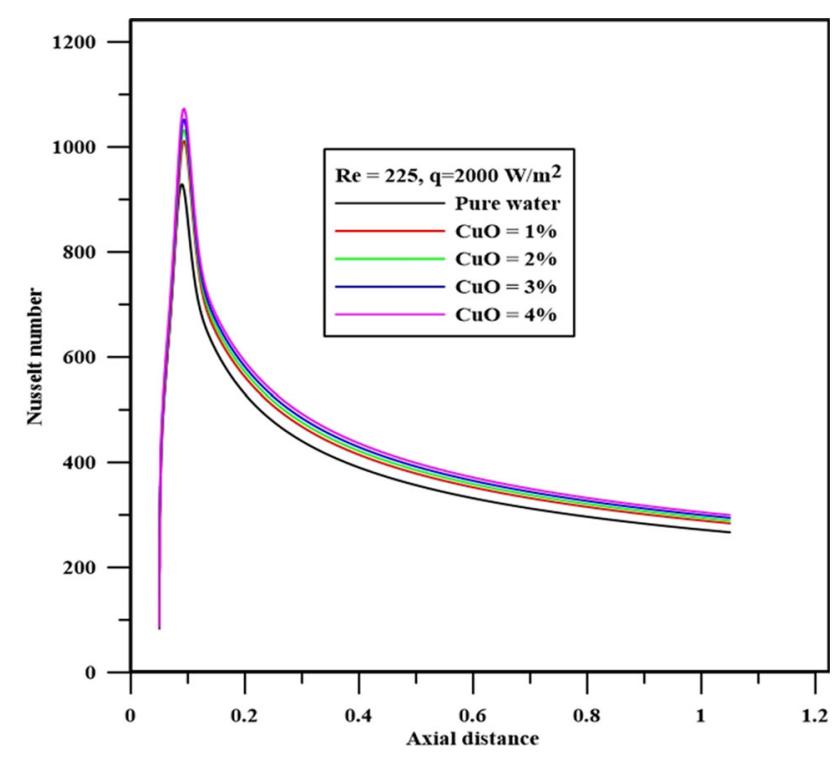

Fig. 8 Variation of local Nusselt number with different volume fraction of nano-fluids

\section{Effect of volume fraction}

Figures 8 and 9 show effect of volume fractions of $\mathrm{CuO}$ nanoparticles and pure water on local Nusselt number and pressure drop with axial distance for backward-facing step without obstacle and Reynolds number of 225, respectively. It is clear observed that for all cases increases in Nusselt number with increased of volume fractions of $\mathrm{CuO}$ nanoparticles where the highest Nusselt number obtained with $4 \%$ of volume fractions of $\mathrm{CuO}$ nanoparticles due to increase of thermal conductivity of base liquid which

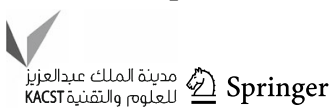




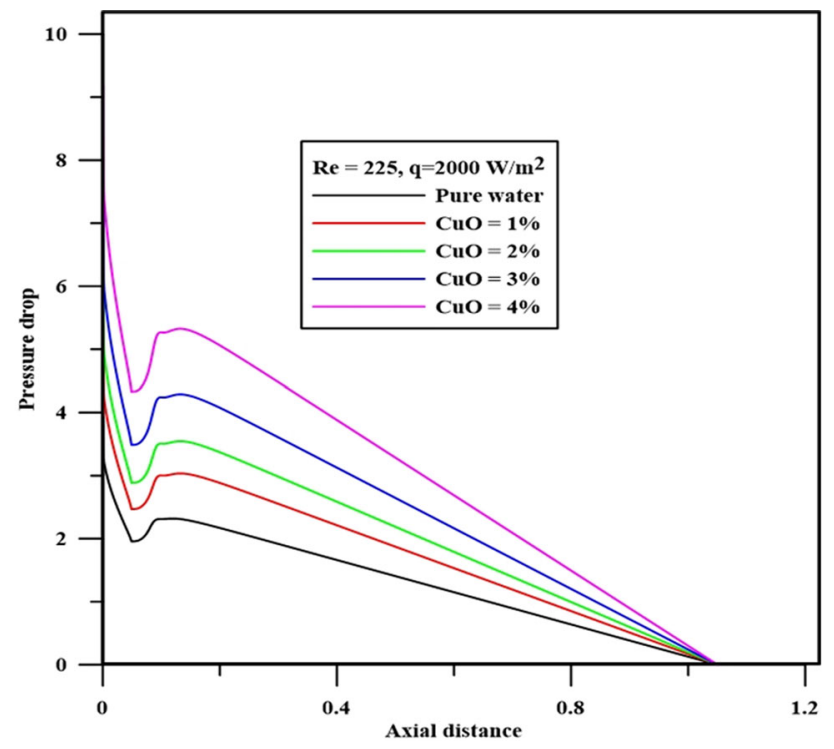

Fig. 9 Variation of local pressure drop with different volume fraction of nano-fluids

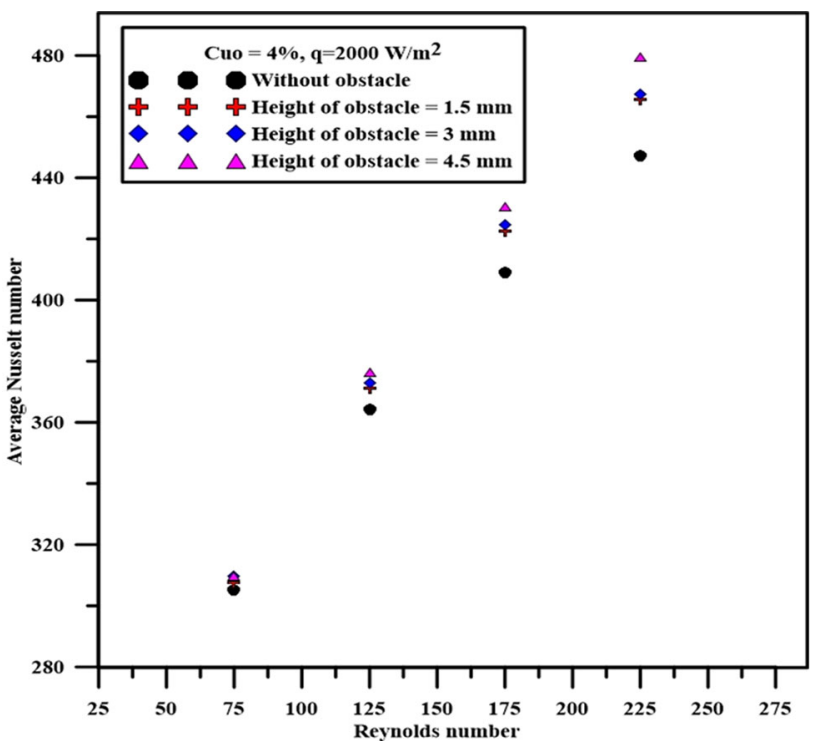

Fig. 10 Average Nusselt number with different of Reynolds number and four different configurations

represented the augmentation in heat transfer. Also increase in pressure drop has been seen with rise of volume fractions of $\mathrm{CuO}$ nanoparticles, and maximum pressure drop occurred at $4 \%$ volume fractions of $\mathrm{CuO}$ nanoparticles.

\section{Average Nusselt number and pressure drop}

In this section, the average Nusselt number and pressure drop with different of Reynolds number and four different

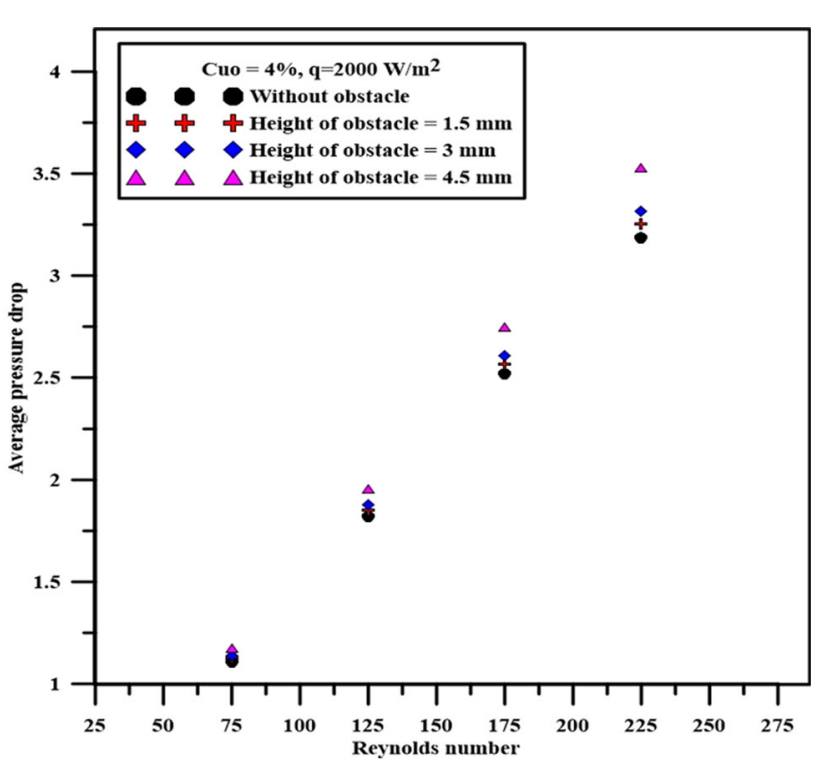

Fig. 11 Average pressure drop with different of Reynolds number and four different configurations

configurations of backward-facing step for $4 \%$ of volume fractions of $\mathrm{CuO}$ nanoparticles are presented in Figs. 10, 11. It is noticed that increase in average Nusselt number with increase both Reynolds number and height obstacle in flow channel. The maximum thermal performance was about $22 \%$ for backward-facing step with obstacle of $4.5 \mathrm{~mm}$, Reynolds number of 225 , and $4 \%$ of $\mathrm{CuO}$ nanoparticles compared with backward-facing step without obstacle. Increase in pressure drop observed with increase of Reynolds number and height obstacle where the maximum pressure drop found with Reynolds number of 225 and height obstacle of $4.5 \mathrm{~m}$ compared with others.

\section{Streamline of velocity}

Figure 12 shows the contour streamline of velocity for backward-facing step (without obstacle, with obstacle of $1.5 \mathrm{~mm}$, with obstacle of $3 \mathrm{~mm}$, with obstacle of $4.5 \mathrm{~mm}$ ) for Reynolds number of 225. The results show that the main recirculation region is seen for all cases after inlet region of backward-facing step, but two recirculation regions appeared after and before each obstacle. The size of recirculation region observed increase after obstacle with increased height obstacle while decreases before the obstacle due to, as the flow velocity rises, the recirculation regions after obstacle are enlarged while before the obstacle are compressed. The maximum recirculation region found with height obstacle of $4.5 \mathrm{~mm}$ compared with others which has significant effect on the thermal performance. 
(a)

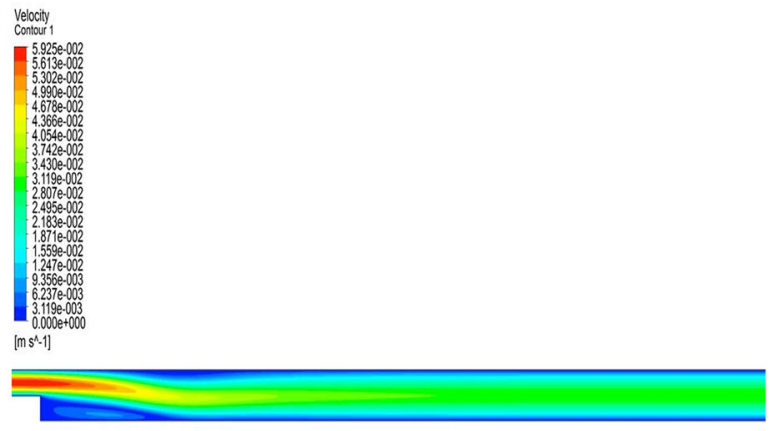

(b)

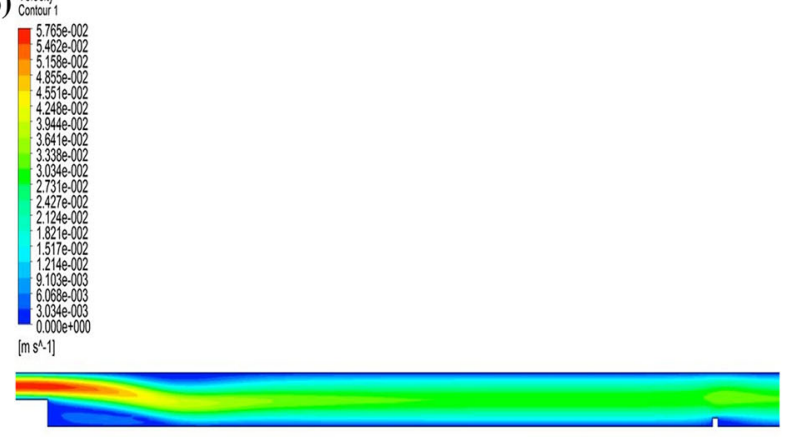

(c)

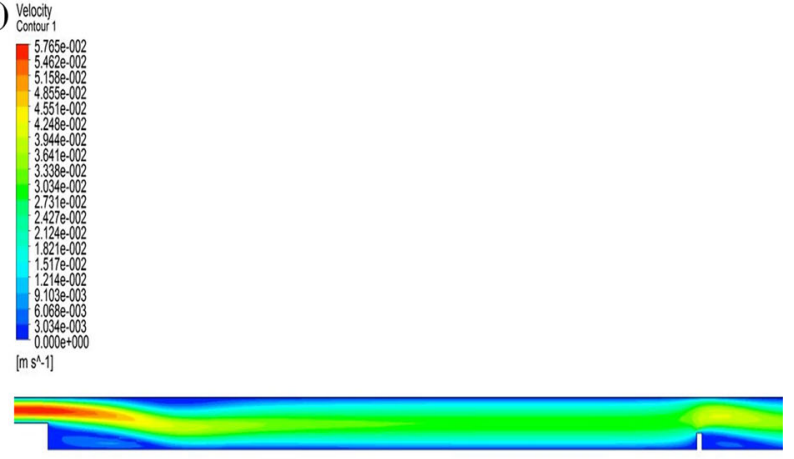

(d)

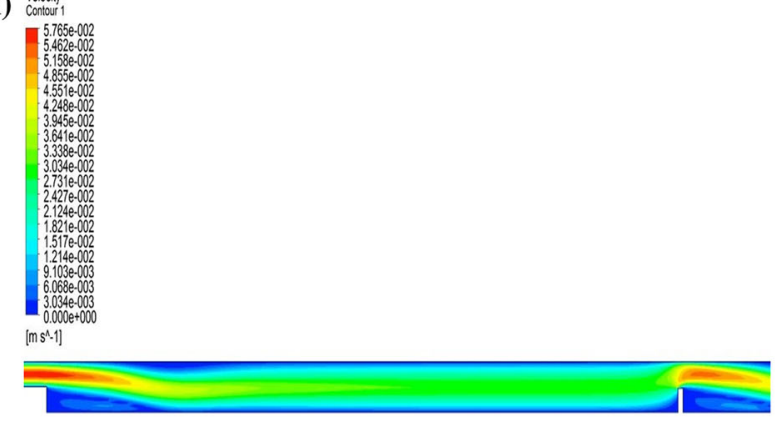

Fig. 12 Contour streamline of velocity for (a) without obstacle, (b) with obstacle of $1.5 \mathrm{~mm}$, (c) with obstacle of $3 \mathrm{~mm}$, (d) with obstacle of $4.5 \mathrm{~mm}$

\section{Conclusion}

Numerical simulation of two-dimensional laminar heat transfer in a backward-facing step with and without obstacle using nano-fluids was studied. Finite volume method was used for solving governing equations with suitable boundary conditions. The numerical results were presented for four different configurations of backward-facing step (without obstacle, with obstacle of $1.5 \mathrm{~mm}$, with obstacle of $3 \mathrm{~mm}$, with obstacle of $4.5 \mathrm{~mm}$ ), Reynolds number range varied from 75 to 225 , and volume fractions of nanofluids varied from 1 to $4 \%$, at constant heat flux. The obtained results found that Nusselt number increases with increase of Reynolds number and height of obstacle for all cases where the maximum Nusselt number was observed with higher Reynolds number and $4.5 \mathrm{~mm}$ height obstacle. Effect of volume fractions of $\mathrm{CuO}$ nanoparticles on local Nusselt number was investigated where the maximum Nusselt number found with $4 \%$ of volume fractions of $\mathrm{CuO}$ nanoparticles. Also Effects of Reynolds number, height obstacle, and volume fractions of $\mathrm{CuO}$ nanoparticles on pressure drop were considered. Recirculation regions at inlet of backward-facing step and before and after each obstacle were observed in counter streamline of velocity. The biggest thermal augmentation was found for Reynolds number of 225 , height obstacle of $4.5 \mathrm{~mm}$, and $4 \%$ of volume fractions of $\mathrm{CuO}$ nanoparticles.

Open Access This article is distributed under the terms of the Creative Commons Attribution License which permits any use, distribution, and reproduction in any medium, provided the original author(s) and the source are credited.

\section{References}

Abu-Nada E (2008) Application of nanofluids for heat transfer enhancement of separated flows encountered in a backward facing step. Int J Heat Fluid Flow 29(1):242-249

Addad Y, Laurence D, Talotte C, Jacob MC (2003) Large eddy simulation of a forward-backward facing step for acoustic source identification. Int J Heat Fluid Flow 24(4):562-571

Al-aswadi AA, Mohammed HA, Shuaib NH, Campo A (2010) Laminar forced convection flow over a backward facing step using nanofluids. Int Commun Heat Mass Transf 37(8):950-957

Armaly BF, Durst F, Pereira JCF, Schönung B (1983) Experimental and theoretical investigation of backward-facing step flow. J Fluid Mech 127:473-496

Corcione M (2010) Heat transfer features of buoyancy-driven nanofluids inside rectangular enclosures differentially heated at the sidewalls. Int J Therm Sci 49:1536-1546

Emad S, Hussein T, Mohammad M, Parvaneh SN, Sara TL, Tuqa A, Kazi SN, Hendrik SCM (2015) An experimental and numerical investigation of heat transfer enhancement for graphene nanoplatelets nanofluids in turbulent flow conditions. Int J Heat Mass Transf 81:41-51

Incropera FP (2007) Fundamentals of heat and mass transfer. Wiley, New York

Kawamura T, Tanaka S, Mabuchi I, Kumada M (1987) Temporal and spatial characteristics of heat transfer at the reattachment region of a backward-facing step. Exp Heat Transf 1(4):299-313

Kelkar KM, Patankar SV (1987) Numerical prediction of flow and heat transfer in a parallel plate channel with staggered fins. J Heat Transf 109(1):25-30 
Khanafer K, Al-Azmi B, Al-Shammari A, Pop I (2008) Mixed convection analysis of laminar pulsating flow and heat transfer over a backward-facing step. Int $J$ Heat Mass Transf 51(25-26):5785-5793

Koo J, Kleinstreuer C (2005) Impact analysis of nanoparticle motion mechanisms on the thermal conductivity of nanofluids. Int Commun Heat Mass Transf 32:1111-1119

Lima RC, Andrade CR, Zaparoli EL (2008) Numerical study of three recirculation zones in the unilateral sudden expansion flow. Int Commun Heat Mass Transf 35(9):1053-1060

Mori Yuaks Y (1986) A study of the time and spatial micro- structure of heat transfer performance near the reattaching point of separated flows. Trans JSME B52:3353-3361

Oon CS, Togun H, Kazi SN, Badarudin A, Zubir MNM, Sadeghinezhad E (2012) Numerical simulation of heat transfer to separation air flow in an annular pipe. Int Commun Heat Mass Transf 39(8): 1176-1180

Oyakawa K, Teruya I, Senaha I, Yaga M, Mabuchi I (1996) Evaluation of thermal performance on heat transfer enhancement by passive and active methods at downstream region of backward-facing step. Trans Jpn Soc Mech Eng Ser B 62(595): 1104-1110

Patankar SV (1980) Numerical heat transfer and fluid flow. McGrawHill book company

Safaei MR, Togun H, Vafai K, Kazi SN, Badarudin A (2014) Investigation of heat transfer enhancement in a forward-facing contracting channel using FMWCNT nanofluids. Numer Heat Transf Part A Appl 66(12):1321-1340

Togun H, Salman YK, Sultan Aljibori HS, Kazi SN (2011) An experimental study of heat transfer to turbulent separation fluid flow in an annular passage. Int $\mathbf{J}$ Heat Mass Transf 54(4):766-773

Togun H, Safaei MR, Sadri R, Kazi SN, Badarudin A, Hooman K, Sadeghinezhad E (2014a) Numerical simulation of laminar to turbulent nanofluid flow and heat transfer over a backwardfacing step. Appl Math Comput 239:153-170

Togun H, Tuqa A, Kazi SN, Badarudin A, Ariffin MKA, Zubir MNM (2014b) Numerical study of heat transfer and laminar flow over a backward facing step with and without obstacle. Int J Mech Ind Sci Eng World Acad Sci Eng Technol 8:361-365

Togun H, Ahmadi G, Abdulrazzaq T, Shkarah AJ, Kazi SN, Badarudin A, Safaei MR (2015) Thermal performance of nanofluid in ducts with double forward-facing steps. J Taiwan Inst Chem Eng 47:28-42

Vajjha RS, Das DK (2009) Experimental determination of thermal conductivity of three nanofluids and development of new correlations. Int J Heat Mass Transf 52:4675-4682

Yu KF, Lee Eric WM, Yuen Jason KK (2009) High and low Reynolds number two-phase flows over a backward-facing step by 2D and 3D large Eddy simulation. Int J Nonlinear Sci Numer Simul 10(9):1135-1157 